Archived version from NCDOCKS Institutional Repository http://libres.uncg.edu/ir/asu/

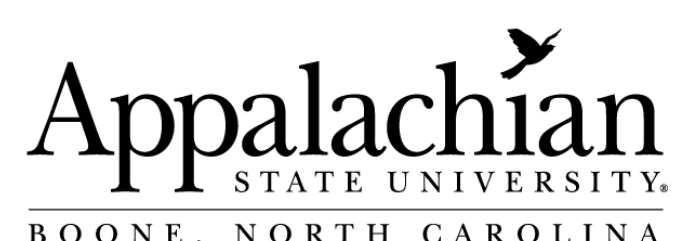

\title{
Hot Spots And Blind Spots: Geographical Clusters Of Firms And Innovation
}

\author{
By: Richard Pouter and Caron H. St. John
}

\begin{abstract}
Hot spots are fast-growing geographic clusters of competing firms. Drawing on several literature streams, we develop an evolutionary model that contrasts hot spot and non-hot spot competitors within the same industry. Initially, economies of agglomeration, institutional forces, and managers' mental models create an innovative environment within the hot spot. Over time those same forces create a homogeneous macroculture that suppresses innovation, making hot spot competitors more susceptible than non-hot spot competitors to environmental jolts.
\end{abstract}

Pouder, Richard, and Caron H. St. John. "Hot Spots and Blind Spots: Geographical Clusters of Firms and Innovation." The Academy of Management Review, vol. 21, no. 4, 1996, pp. 1192-1225. DOI: 10.2307/259168. JSTOR, JSTOR. Publisher version of record available at: www.jstor.org/stable/259168. 


\title{
HOT SPOTS AND BLIND SPOTS: GEOGRAPHICAL CLUSTERS OF FIRMS AND INNOVATION
}

\author{
RICHARD POUDER \\ CARON H. ST. JOHN \\ Clemson University
}

\begin{abstract}
Hot spots are fast-growing geographic clusters of competing firms. Drawing on several literature streams, we develop an evolutionary model that contrasts hot spot and non-hot spot competitors within the same industry. Initially, economies of agglomeration, institutional forces, and managers' mental models create an innovative environment within the hot spot. Over time, those same forces create $\alpha$ homogeneous macroculture that suppresses innovation, making hot spot competitors more susceptible than non-hot spot competitors to environmental jolts.
\end{abstract}

[T]raditional hot spots are turning into sewers. (Gupta, 1992: B2)

Fast-growing, geographically clustered firms within industriessometimes referred to as hot spots-have become an increasingly important part of the competitive landscape. As Porter observed, the geographic concentration of firms in the same industry is "strikingly common around the world" (1990: 120). For example, Business Week (1992), estimated that 600,000 Americans were employed in 15 high-tech hot spots, and many new hot spots were still emerging. In the United States, a few examples of hot spots include the laser and electro-optics industry in Orlando, Florida, the biotechnology and communications industries in San Diego, California, the computer manufacturing and computer chip industry in Austin, Texas, and the ceramics industry in Corning, New York. In Europe, hot spot locations include the Scientific City in France, the ceramics industry in Sassuolo, Italy, auto manufacturing in the Basque Region, and medical instruments in Tuttlingen, Germany. Because firms in hot spots play an increasingly important role in job creation and technological innovation, it is important to understand why hot spots form, how geographical clustering affects the behavior of hot spots over time, and what the ultimate effect of clustering is on firms' innovation and success.

Evidence has shown that competitors in former hot spots, such as Route 128 in Boston, Massachusetts (minicomputers), and the Minneapolis, Minnesota, area (mainframes), have experienced great declines in growth, accompanied by economic devastation. This rise-and-fall pattern suggests

The authors, listed in alphabetical order, are equal contributors on this article. The authors thank Marlene Fiol and AMR's anonymous reviewers for their encouragement and guidance. 
that some geographically clustered groups of competitors may experience evolutionary phases similar to those experienced by larger industry populations. Initially, highly innovative new entrants to a geographical cluster grow dramatically (Florida \& Kenney, 1990), creating an identity (hot spot) for the clustered firms. Over time, however, failures prevail among individual firms, and the performance of the hot spot deteriorates (Suskind, 1992). Indeed, the quote preceding this article vividly describes the demise of hot spots.

Although researchers in industrial organization, organizational ecology, and economic geography have documented the tendency of groups of firms within industries to cluster in geographical space (Bania, Calkins, \& Dalenberg, 1992; Lomi, 1995; Maarten de Vet \& Scott, 1992; Melecki, 1985; Porter, 1990; Rees \& Stafford, 1986; Saxenian, 1994; Scott, 1989), hot spots are generally an understudied phenomenon in the organization sciences (DeNoble \& Galbraith, 1992). As Scott noted, "Indeed it may be said that the question of the initiation and early consolidation of growth centers in capitalism (from 19th century Lancashire to Henry Ford's Detroit to Silicon Valley) has never really been satisfactorily addressed or resolved" (1989: 91).

In this article, we follow the lead of Baum and Mezias (1992: 599), who called for research that examines "the relationship between localized competition and the dynamics of organizational founding, growth, and transformation. Such research would help to specify more fully the significance of localized competitive processes for population dynamics and organizational evolution." In developing our research propositions about the behavior of clustered groups of competitors within a larger industry population and the effects on innovation, we drew from the following research streams: (a) punctuated equilibrium and innovation (Gersick, 1991; Tushman \& Romanelli, 1989), (b) organizational ecology (Aldrich \& Fiol, 1994; Baum \& Mezias, 1992; Hannan \& Carroll, 1992; Hannan \& Freeman, 1977, 1989; Lomi, 1995), (c) economic geography (Bania et al., 1992; Scott, 1992), (d) industrial organization and the resource-based view of the firm (Barney, 1991; Grant, 1991; Mahoney \& Pandian, 1992; Porter, 1980), (e) institutional theory (DiMaggio \& Powell, 1983; Oliver, 1991; Powell, 1991; Zucker, 1983), and (f) cognitive theories (Kielser \& Sproull, 1982; Nisbett \& Ross, 1980; Porac, Thomas, \& Emme, 1987; Reger \& Huff, 1993).

In this article, we argue that a clustered subgroup of competitors within an industry will likely move through three evolutionary phases that pattern the punctuated equilibrium model: (a) origination of the cluster and emergence of the hot spot identity, (2) convergence of clustered firms, and (3) firm reorientation, which includes a decline in the performance of the cluster or hot spot (Tushman \& Romanelli, 1985). For each phase, we discuss the role that resource economies, cognitive frameworks, and institutional forces play in influencing competitive behavior and levels of innovation. For each phase, we also show how the hot spot evolution 
differs from the overall industry evolution captured by a typical industry life cycle.

We propose that the economies of agglomeration ${ }^{1}$ that initially draw firms together eventually erode. We also argue that the competitive strategies of firms in a given hot spot, which are initially highly innovative, tend to be less innovative over time because firms define their field of competition as the hot spot to which they belong, rather than as the total industry population. We propose that this restricted perspective gives rise to competitive "blind spots" (Porter, 1980: 59), which limit firms' innovative potential and adversely affect their performance.

\section{THEORETICAL FOUNDATION}

\section{Definitions}

According to the popular business literature discussed in the introduction, hot spots are described as high-growth, usually technologically based, and geographically clustered groups of competing firms. Although commonly discussed in the business literature, a hot spot is a context that lacks formal definition in the research literature. For this article, we provide the following definition:

Hot Spot: Regional clusters of firms that (a) compete in the same industry, (b) begin as one or several start-up firms that, as a group, grow more rapidly than other industry participants (sales and employment levels), and (c) have the same or very similar immobile physical resource requirements in the long run. ${ }^{2}$

We argue that hot spots appear to undergo an evolutionary process, which may have a negative impact on innovation in the long run. In order to better understand this evolutionary process, we must clarify our use of the term innovation, which has been variously defined in the literature.

Innovation: (a) the new products or services, new processes, and new organizational structures that firms use to compete with one another and meet customer demand; (b) the adoption of a new idea, process, product, or service, developed internally or acquired from the external environment as a function of a firm's technical, strategic, and administrative skills. (Nelson \& Winter, 1982)

\footnotetext{
${ }^{1}$ According to Arthur (1990: 237), there are economies of agglomeration "if the net benefits to being in a location together with other firms increase with the number of firms in the location."

${ }^{2}$ Not all geographical clusters of competitors become hot spots as we have defined them. Firms that are located near one another in order to capture a local market opportunity would not constitute a hot spot. For example, managers of hotels, retail establishments, and restaurants consider the availability of customers when making location decisions, but these companies would not form hot spots (see Baum \& Menzias, 1992; Gripsrud \& Gronhaug, 1985).
} 


\section{Overview of the Theoretical Framework}

Organization innovation is subject to individual, organizational, and environmental influence (Damanpour, 1991). Although most research has been focused on the individual and organizational factors that play a key role in the ability of an organization to adopt innovations, the extraorganizational context, particularly the industry group, also influences innovativeness (Van de Ven, 1986). In this article, we focus on the literature that develops an industry-level context for the study of innovation.

In studies of innovation from an industry perspective, Van de Ven and Garud (1989) defined an industry as a social system that governs, integrates, and performs all of the functions required to transform technological innovations into commercially viable products. They argued that the social system constituting an industry emerges over time through a process of accumulation, and moves through stages from initiation to start-up. In the following sections we develop a similar dynamic view of geographical clusters of firms and argue that, under certain conditions, they will behave as a subpopulaion of a larger population and will have similar resources, cost structures, mental models, and competitive behavior. As a result, the geographical cluster will have different rates and areas of innovation compared to the larger industry population.

We develop our model of subpopulation evolution using the organizational evolutionary stages described in the punctuated equilibrium model (Tushman \& Romanelli, 1985) and by the idea of deep structure (Gersick, 1991). According to punctuated equilibrium concepts, the emergence and evolution of an industry are characterized by alternating periods of industry cooperation and industry competition, which create patterns of industry convergence. The pattern of convergence is initiated by the creation of an organizational deep structure. For the punctuated equilibrium model, deep structure is defined as "a network of fundamental interdependent choices of the basic configuration into which a system's units are organized, and the activities that maintain both this configuration and the system's resource exchange with the environment" (Gersick, 1991: 15). We chose the punctuated equilibrium model as our organizing framework because it highlights the interaction between a firm's behavior and an industry's behavior, unlike organizational life-cycle and teleological process theories of organizational development and change (see Van de Ven \& Poole, 1995) that are focused primarily on organizational factors.

The thesis of our model is that geographical clustering can lead to resource arrangements and costs, mental models, and patterns of competitive behavior that create a deep structure within the cluster. The deep structure causes competitors within the cluster to behave differently from competitors outside the cluster, to assess competitor and market trends differently, and, ultimately, to become vulnerable to naive industry assumptions and imitative behavior that leads to unproductive innovative efforts. The result is two separate evolutionary paths for clustered and 
nonclustered competitors. Initially, clustered firms experience resource cost and access advantages, heightened competitor awareness, and enhanced legitimacy, which allow the cluster to dominate industry growth and innovation, leading to the hot spot identity. Over time, however, the clustered firms begin to experience resource diseconomies, insular competitive practices, less frequent innovation, and lost dominance in the industry.

The pattern of hot spot evolution captured by the punctuated equilibrium model is cast against a background of overall industry evolution. The hot spot initially grows faster than the industry, but then it experiences declines not felt by the competitors outside of the hot spot, as shown in Figure 1. Within the punctuated equilibrium framework, a macroview of the dynamic processes of innovation is culled from the following research streams: (a) population ecology, (b) industrial organization (particularly within a regional or geographic context), (c) institutions, and (d) managerial cognition. The major theoretical elements we use in our model are summarized in Table 1, and their relationships are shown in Figure 2.

\section{THE ORIGINATION PHASE OF HOT SPOTS}

Organization ecologists have indicated that firms sometimes cluster in an area after an initial start-up to seize a niche-a particular combination of resources required to support a given type of organizational population (Hannan \& Freeman, 1989). Lomi observed that "the recurrence of patterns of organizational concentration in space across different industries and in a number of national contexts provides indirect evidence that location may be a general factor shaping the evolution of organizations" (1995: 111). If location provided an evolutionary advantage, then

FIGURE 1

\section{Hot Spot versus Non-Hot Spot Growth}

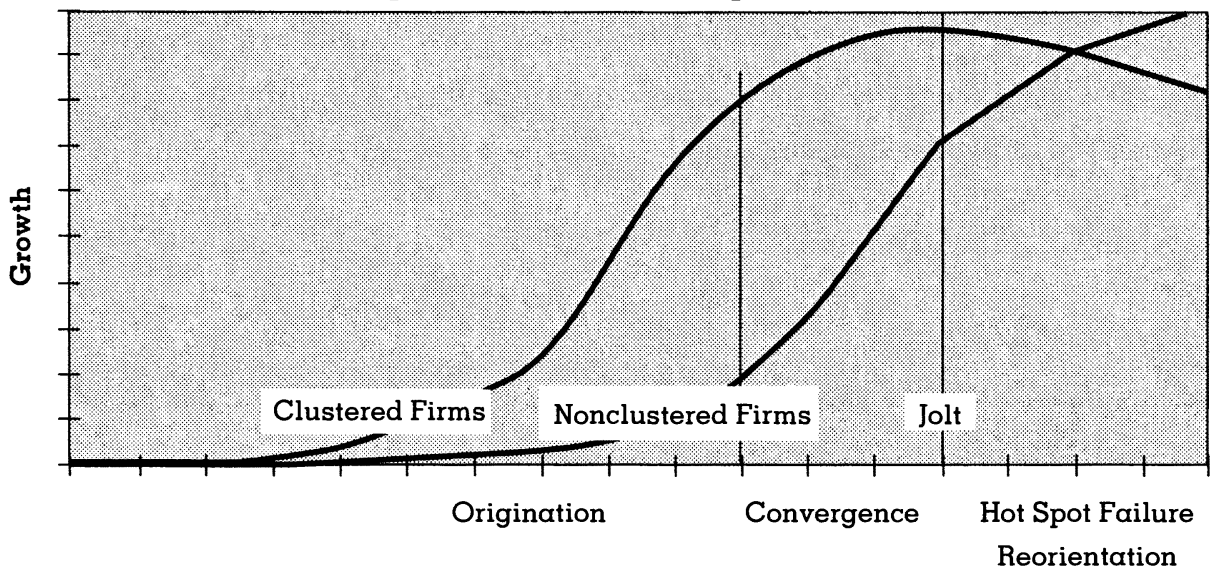

Time 
TABLE 1

Theoretical Foundations Applied to Competitive Behavior and Innovation in Hot Spots

\begin{tabular}{|c|c|c|}
\hline Theoretical Foundation & Specific Application & $\begin{array}{c}\text { Relationship to Behavior of } \\
\text { Hot Spot }\end{array}$ \\
\hline $\begin{array}{l}\text { Punctuated equilibrium } \\
\text { model }\end{array}$ & $\begin{array}{l}\text { Origination } \\
\text { Convergence } \\
\text { Reorientation } \\
\text { Deep structure }\end{array}$ & $\begin{array}{l}\text { Growth } \\
\text { Stabilization } \\
\text { Decline and realignment } \\
\text { Entrenchment } \\
\text { Environmental jolts }\end{array}$ \\
\hline Organization ecology & $\begin{array}{l}\text { Populations and } \\
\text { subpopulations }\end{array}$ & $\begin{array}{l}\text { Competition and growth in } \\
\text { subpopulations and } \\
\text { populations }\end{array}$ \\
\hline Resource-based theory & $\begin{array}{l}\text { Competitive advantage } \\
\text { Competitive parity }\end{array}$ & $\begin{array}{l}\text { Specialized resources and } \\
\text { information } \\
\text { Change in resources }\end{array}$ \\
\hline Institutional theory & $\begin{array}{l}\text { Organization field } \\
\text { Collectivities } \\
\text { Isomorphism }\end{array}$ & $\begin{array}{l}\text { Legitimacy } \\
\text { Macrocultures } \\
\text { Inertia }\end{array}$ \\
\hline Management cognition & $\begin{array}{l}\text { Information salience } \\
\text { Cognitive bias }\end{array}$ & $\begin{array}{l}\text { Competitors' mental models } \\
\text { Bias in the competitors' } \\
\text { assessment }\end{array}$ \\
\hline Economic geography & Economies of agglomeration & Reasons for cluster formation \\
\hline
\end{tabular}

FIGURE 2

Forces Affecting the Evolution of Hot Spots

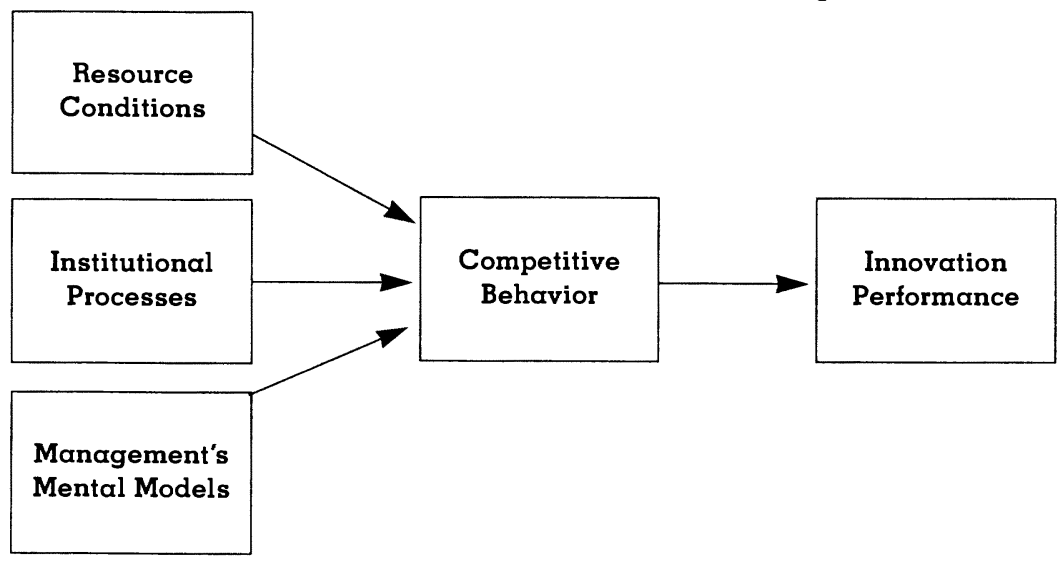


organizational populations would not be homogeneous, geographical proximity would play a role in competitive behavior, and birth and death rates for firms would vary systematically across locations (Baum \& Mezias, 1992; Lomi, 1995). Firms clustered in one location would define a subpopulation within the total industry population, face different resource availability and competitive practices, and could evolve independently of other industry participants (Hannan \& Carroll, 1992). The organizational ecology literature, therefore, supports the notion that geographically clustered firms may differ from firms outside the cluster regarding cost structures, competitive behavior, and performance over time.

In the following paragraphs on the origination of hot spots, we use arguments from the resource-based theory of the firm, institutional theory, and cognitive theory to explain (a) why clusters form, (b) where clusters form, and (c) why the competitive behavior and innovation performance of clustered firms may differ from nonclustered firms within the same industry.

\section{Early Resource Conditions}

As Scott (1992) noted, it is difficult to identify the emergence of a cluster before it occurs. Interest in identifying the precursor conditions has led researchers to study the location factors that would seem to catalyze the emergence of industry clusters: military bases, research universities, science parks, international airports, venture capital firms, and recreational facilities (Markusen, Hall, \& Glasmeir, 1986). Results about the role these factors play in the emergence of clusters have been inconclusive (Haug, 1991). For example, when only precursor location factors are considered, it remains unclear why the semiconductor industry developed in Silicon Valley (Scott, 1989). Stanford University provided engineering personnel and a high-technology industrial park. There were some preexisting electronics firms in the region, and there were many military and aerospace facilities as potential customers in the San Francisco Bay Area. However, equally favorable conditions existed elsewhere, such as in Phoenix, Arizona, and Dallas, Texas (Scott, 1989).

There seems to be an element of chance to the origin and initial location of geographical clusters of firms (Rauch, 1993). In some ways, clusters of firms are analogous to forests of trees. Although one cannot anticipate exactly when or where the first seed will land within a field, once the seed is implanted, it is highly likely more trees will follow. Similarly, clusters of firms sometimes originate from a single fast-growing and successful new start-up firm (Saxenian, 1994). If several new firms spin off from a common parent, or set of parents, then a cluster of like firms could begin spontaneously (Maarten de Vet \& Scott, 1992). For example, 31 semiconductor firms were started in Silicon Valley during the 1960s, and a majority could trace their lineage to Fairchild Semiconductor (Saxenian, 1994). In a survey of software firms in Washington state (a region with a high concentration of software industry employment and sales), Haug 
(1991) found that $52 \%$ of new-firm founders were employed within the software industry in Washington before starting their own businesses. When firms are started by entrepreneurs who leave existing organizations, quality-of-life features, existing knowledge of suppliers, and familiarity with the labor market can play a role in the decision to stay in the region (Haug, 1991).

Once the initial site is implanted-through spontaneous spin-off or location factors - there are compelling economic and institutional reasons for new start-ups to continue to locate near competitors. As the first firm becomes successful, qualified suppliers, skilled workers, and informed investors become available, which lowers the cost of entry for subsequent firms, making the area relatively more attractive than other areas. These cost advantages within the cluster are called agglomeration economies (Rauch, 1993; Scott, 1992). Agglomeration economies encourage growth in numbers of new firms, which are either attracted by the technical and resource base or created from spin-offs in the region (Melecki, 1985). As Scott noted:

\begin{abstract}
Because the growth of any complex also brings about a combinatorial extension of the set of interfirm transactional possibilities, the organizational flexibility of the whole system tends by the same token to increase. Individual producers are able to build and rebuild external contacts with increasing ease and speed, which means they can change all the more readily. The proliferation of increasingly more specialized producers in any given complex tends to result in continual reduction of the costs of production. (1989: 29)
\end{abstract}

\title{
Institutional Processes
}

In addition to the benefits of lower costs and superior resources for clustered firms, firms also have an incentive to cluster to enhance legitimacy and avoid the liability of newness (Aldrich \& Fiol, 1994; Singh, Tucker, \& House, 1986). One primary method for enhancing legitimacy is to participate in interfirm relationships within the cluster (Scott, 1989). In high-technology hot spots, such as Silicon Valley, Route 128, the Scientific City in France, and the ceramics production complex in Sassuolo, Italy, competitors have formed intricate networks of interdependencies (Porter, 1990; Scott, 1989). They share ties to a research base such as a university (including consulting researchers, laboratories, and libraries), a skilled labor pool, a network of highly qualified suppliers, and a knowledgeable pool of venture capitalists (Bania et al., 1992; Maarten de Vet \& Scott, 1992; Porter, 1990; Rees \& Stafford, 1986; Scott, 1989). Efforts to create interrelationships encourage the initial formation of the cluster, and these relationships hold the cluster together over time (Scott, 1989).

Groups of proximal rivals stimulate creation of a local infrastructure and expanded supply of skilled labor and resources (Porter, 1990). As groups of local competitors work quickly to create an industry's infrastructure and credibility, they derive cost and time savings through their affilia- 
tion and proximity (Porter, 1990; Scott, 1989). As the emerging industry subpopulation gains legitimacy within the region, access to capital and markets improves (Aldrich \& Fiol, 1994; Suchman, 1995). Thus, with an increased number of organizations comes increased legitimacy (Hannan \& Freeman, 1989).

Therefore, once firms begin to amass in one area, they experience agglomeration economies and subgroup legitimacy that fuel growth of the cluster, and this is at the expense of growth among nonclustered firms. Clustered firms develop a form of first-mover advantage that discourages formation of other clusters or agglomerations (Scott, 1989, 1992). Although membership in the geographical cluster is not a requirement for participation in an industry, proximity lowers the cost and risk of firms' entering the industry and contracting for resources and services (Bania et al., 1992). These arguments lead to our first proposition.

Proposition 1: During the origination phase of evolution, geographically clustered firms will experience greater cost economies and legitimacy than industry competitors that are outside of the cluster.

\section{Early Managerial and Organizational Mental Models}

In addition to the cost and access characteristics of the industry cluster, there is a cognitive dimension as well. Within an emerging cluster, several factors create a propensity for managers and key technical employees to have similar cognitive frameworks or mental models. ${ }^{3}$ Building on research in top management cognition, we believe that the fact that managers and employees are all participating in the same industry suggests they have similar industry experiences and technical training (Huff, 1982; Prahalad \& Bettis, 1986; Spender, 1989). For example, in the case of managers and employees of a high-technology industry, specific technical education available at a few research institutions would create common or similar educational experiences and affiliations, and, in all likelihood, draw from a common age cohort. That individuals want to identify with and take part in the particular business opportunity suggests that their values and perceptions are similar (e.g., a propensity toward entrepreneurship and risk taking). All of these factors work together, increasing the likelihood that the mental models of managers and employees are somewhat similar, even at the earliest stages of the hot spot formation.

Once an agglomeration of firms has begun to form, the experiences of firms within the cluster would promote the continued evolution of similar mental models of strategists and managers. According to Gersick (1991), the experiences of firms in the early stage of innovation influence creation

\footnotetext{
${ }^{3}$ Following Walsh's definition (1995: 286), we define a mental model or knowledge structure as "a mental template consisting of organized knowledge about an information environment that enables interpretation and action in that environment."
} 
of managers' deep structures and the cognitive frameworks, which, in turn, establish the competitive rules of the game. For example, managers are more attentive to the actions of firms in their subpopulation because segregating mechanisms that distinguish organizational subpopulations also act to focus the attention of managers (Hannan \& Freeman, 1989; Haveman, 1993). In the case of clusters, geographical proximity and the attendant interdependent resource base act as segregating mechanisms.

Several authors have identified geographical proximity as a segregating mechanism that influences managers' mental models of competitors. In describing such mental models, Porac, Thomas, and Emme (1987) proposed that these models will be more complex for frequent competitors and will incorporate focal categories of perceived organizational characteristics, including location, to discern competitors from noncompetitors. Porac, Thomas, and Baden-Fuller (1989) provided indirect evidence for the previous research, noting that psychological segmentation of competitors in the Scottish knitwear industry was supported by the industry's geographical homogeneity.

In geographical clusters, proximity makes information about local competitors more available because managers are better able to scan the activities of local competitors compared to the activities of outside competitors. Frequent social and professional interactions, dependence on a common supplier base, and recruitment from a common, highly mobile professional labor pool would lead to a high level of information exchange among managers and an awareness of the capabilities of local competitors (Porter, 1990; Reger \& Huff, 1993; Saxenian, 1994; Scott, 1989). Moreover, the face-to-face interaction that underlies these forms of information exchange is superior for interpreting social cues, capturing psychoemotional reactions, and resolving uncertain and ambiguous issues (Nohria \& Eccles, 1992). Information available to managers about local competitors' innovative activities could be increased in a number of ways, which are further discussed in Table 2.

As they face an expanding cluster of competitors, managers would also face limited memory capacity for storage and retrieval of information on competitors. In attempting to use limited memory capacity efficiently, managers will store information according to its availability (Tversky \& Kahneman, 1973). Information that is readily available in memory can be linked to events and examples that dominate a person's settings; such information and events are said to be salient (Fiske \& Taylor, 1991). Consistent with the greater availability of information on nearby competitors, managers in hot spots will find such information to be salient. ${ }^{4}$

The previous discussion implies that the mental models of managers in clusters will be greatly influenced by their local competitors, thereby

\footnotetext{
${ }^{4}$ Among the salient events selectively attended to and stored in memory are those that are sharply drawn, including the behaviors and outcomes of competitors (Keisler \& Sproull, 1982).
} 


\title{
TABLE 2 \\ Why Information About Local Competitors is More Salient
}

\begin{abstract}
Mobile Labor Force
Information about competitors' activity seeps from one firm to the next as mobile workers move from employer to employer within the cluster. Mobility and recruitment opportunities are greater within the cluster as managers seek available jobs rather distant jobs, which would uproot their families. For example, in Silicon Valley, $80 \%$ of semiconductor production engineers who quit their jobs moved to another firm in the local labor market (Angel, 1989). The availability of jobs increases job hopping and short job tenure (Saxenian, 1994). As Andy Grove of Intel said, "A popular joke about Silicon Valley is that all you have to do to change jobs is turn left instead of right when you come out of your driveway" (1987: 156).
\end{abstract}

\section{Extrafirm Conversations}

Social interactions in the community can result in information spills and leaks about competitors' plans. Social interactions among proximate competitors take various forms: (a) common membership in political and religious organizations, country and athletic clubs, and community or business professional organizations, such as Rotary: (b) involvement in local arts, athletic, and civic groups, such as children's soccer; and (c) residence in the same neighborhoods, such as Bloomfield Hills, in which Detroit's competing automaker executives interact socially (Yates, 1984).

\section{Cooperative Alliances}

Proximity to university, strategic, supplier, and government alliances means (a) frequent opportunities to discuss and observe competitors' activities (Scott, 1992) and (b) information being exchanged (spilled) through contacts among groups of scientists and engineers (Bania et al., 1992).

\section{Direct Observation}

Firms may observe directly the capacity expansions, technological investments, and hiring efforts of competitors at nearby facilities, which provides clues to competitors' strategies.

\section{Media}

Local newspapers, business journals, television stations, and radio stations will provide more detailed coverage of local competitors, which will increase the speed of response for firms that hear the publicity (Smith \& Grimm, 1991).

increasing opportunities for managers to generalize from the clustered subpopulation to the total industry population. These arguments are supported by organizational ecology theories of density dependence. As noted by Lomi (1995), founders of businesses will be more sensitive to local levels of legitimacy and competition because of their limited capacity to collect information on nonlocal competitors and the ambiguity of interpreting meanings from a distance. In the context of innovation, this suggests that managers would increasingly focus on the innovative activity and capabilities of competitors inside the cluster.

Managers and strategists outside of the cluster, in contrast, will be faced with similar limited memory capacities and incentives to develop simplified mental models, but they will be unlikley to focus on location 
and geography as the basis for that simplification. Outside the cluster, information about competitors inside the cluster will be less salient and less available. Although nonclustered managers and strategists will develop simplified models, they will not simplify using a common location frame of reference. As we show in subsequent sections, the mental models of clustered competitors will play a role in increasing innovation activity in the cluster in the short run, but they will undermine innovative activity in the longer run. The relationships provide a foundation for the following proposition:

Proposition 2: During the origination phase, managers of clustered firms will be more attuned to the strategies and capabilities of competitors inside the cluster compared to competitors outside the cluster. Managers of nonclustered firms will not show a similar tendency.

\section{Competitive Behavior and Innovation}

What are the implications of these resource conditions, legitimizing processes, and mental models for competitive behavior and innovation during the formation phase of hot spot evolution? The shared resource base, agglomeration economies, increased legitimacy, prevalence of simplified mental models, and the salience of local competitor information create a dynamic environment, which we argue is characterized by increasing numbers of clustered firms, emergence of the hot spot identity, a tension between cooperation and intense competition, and high levels of innovation.

Competitive behavior. As proposed in the previous section, competitors within the cluster will experience agglomeration economies that provide access and cost advantages that are not available to nonclustered competitors. Furthermore, the established regional infrastructure of research, suppliers, and labor would make entry and spin-off easier within the cluster than outside the cluster (Porter, 1980; Saxenian, 1994). In keeping with the logic of the resource-based view, competitors outside the region will face higher costs when recruiting and relocating highly specialized employees and when transacting with suppliers and researchers (Grant, 1991; Porter, 1990). They will find it difficult to imitate the complex routines involved in the infrastructure of the clustered subpopulation and will face more imperfect information than clustered firms when assessing the value of industry resources and innovation opportunities (Barney, 1991; Grant, 1991).

The agglomeration economies and shared resources available to firms within the cluster are not a source of competitive advantage for specific clustered firms. Instead, once exploited, they help ensure the survival of clustered firms by creating competitive parity (Barney, 1991) and increasing the probability of economic survival of the cluster as a whole (Porter, 1980). Competitors outside of the cluster would not have access to the cost advantages and enhanced legitimacy of agglomeration, and they would struggle to maintain competitive parity with the clustered competitors. 
The preferential growth conditions within the cluster would result in faster growth for firms within the cluster, leading to the hot spot identity.

Proposition 3: During the origination phase, the rate of growth in numbers of competitors within the cluster will exceed the rate of growth in numbers of competitors outside of the cluster, leading to the hot spot identity.

Industry innovation. During the early stage of hot spot formation, conditions are ripe for high levels of innovation. Three forces work to center industry innovation activity within the hot spot: (a) the increasing number of competitors within the hot spot, many of which are created as spin-offs; (b) the proximity and shared resources among competing firms within the hot spot; and (c) the mental models that emphasize the resources and capabilities of hot spot competitors.

Because new spin-offs are often created in response to an unfilled market need (Haug, 1991), spin-offs are likely to maintain similar supplier and resource arrangements within the cluster to take advantage of agglomeration economies, but they will compete through a strategy that emphasizes differentiation from other hot spot competitors (Baum \& Mezias, 1992). If created by spin-off, the clustered firms are predisposed to a higher level of knowledge about the capabilities and strategic intent of local competitors (Carroll, 1993), which serves as an accurate form of competitive intelligence and can focus the differentiation and innovation efforts of those firms.

Proximity, shared resource arrangements, and an emerging hot spot identity would also contribute to a heightened innovative environment. Clusters are able to harness local pride as a motivating force that energizes firm behavior (Porter, 1990). The entrepreneurial spirit fostered by the large number of spin-offs and start-up firms would fuel a culture of innovation and fast change. Also, the emerging network of alliances among the labor pool, suppliers, idea generators, and competitors would stimulate an environment of creativity and idea exchange (Saxenian, 1994). Finally, formal and informal information exchange among competitors, suppliers, and other related businesses would leak information about competitors and their innovation practices (Baum \& Mezias, 1992; Saxenian, 1994), contributing to firms' well-developed competitive intelligence within the cluster (refer to Table 2).

When the salience of information on local competitors intensifies, managers should have richer mental models of competitors' activities inside the cluster compared to competitors' activities outside the cluster. Deeper knowledge of local competitors and their innovative strategies will enable managers to focus their attention on developing innovations that compete more effectively with local competitors than with outside competitors. To the extent that salience dictates a dichotomy in innovative strategies, managers will have two mental models of competitors' innovative strategies-one for hot spot competitors and one for outside 
competitors. Intense competition and rich mental models would lead to high levels of innovation within the hot spot.

Arguments for intense local competition leading to high levels of innovation within the hot spot are also supported by organizational ecology theory. According to organizational ecology, the intensity of competition among firms is largely a function of the similarity in resource requirements (Hannan \& Carroll, 1992; Hannan \& Freeman, 1989). Although the origination phase of hot spot evolution may be marked by cooperation among competitors to gain legitimacy (Aldrich \& Fiol, 1994; Suchman, 1995), research suggests that the relationships would likely deteriorate, leading to increased competition and spurring industry-level innovation (Van de Ven \& Garud, 1989). Because firms within the cluster compete directly for human, financial, and technological resources, competitive intensity will be higher within the hot spot than among clustered firms and nonclustered firms. Furthermore, the speed, completeness, and accuracy of competitive intelligence among firms within the hot spot, described previously, will allow them to outperform their outside competitors in assessing opportunities for differentiation. Consequently, we would expect the following:

Proposition 4: During the origination phase, clustered firms will be responsible for an increasing proportion of industry innovations, compared to nonclustered competitors.

The resource conditions, institutional processes, and mental models affecting competitive behavior and innovation during the origination phase are summarized in Figure 3.

\section{THE CONVERGENCE PHASE OF HOT SPOTS}

According to the punctuated equilibrium model, convergent periods were described by Tushman and Romanelli (1985: 173) as consisting of "long time spans of incremental change and adaptation which elaborate structure, systems, controls, and resources toward increased coalignment [during which] inertia increases and competitive vigilance decreases" (1985: 215). As Gersick (1991) noted, organizations will make adjustments that preserve their deep structures against internal and external sources of influence. However, many of the assumptions that underlie the deep structure change with growth and success. Although a clustered group of competitors may continue in convergence indefinitely, its role as a hot spot with faster-than-average growth and disproportionate innovative capacity is likely to decline. As we show in the following sections, as time passes, the agglomeration economies and access advantages may erode, and the simplified cognitive frameworks managers used to analyze competitors may no longer represent the most essential phenomena.

\section{Convergence and Resource Conditions}

During the origination phase, firms within the hot spot experience agglomeration economies and the other benefits attached to belonging to 
FIGURE 3

Forces Affecting the Evolution of Hot Spots During the Origination Phase

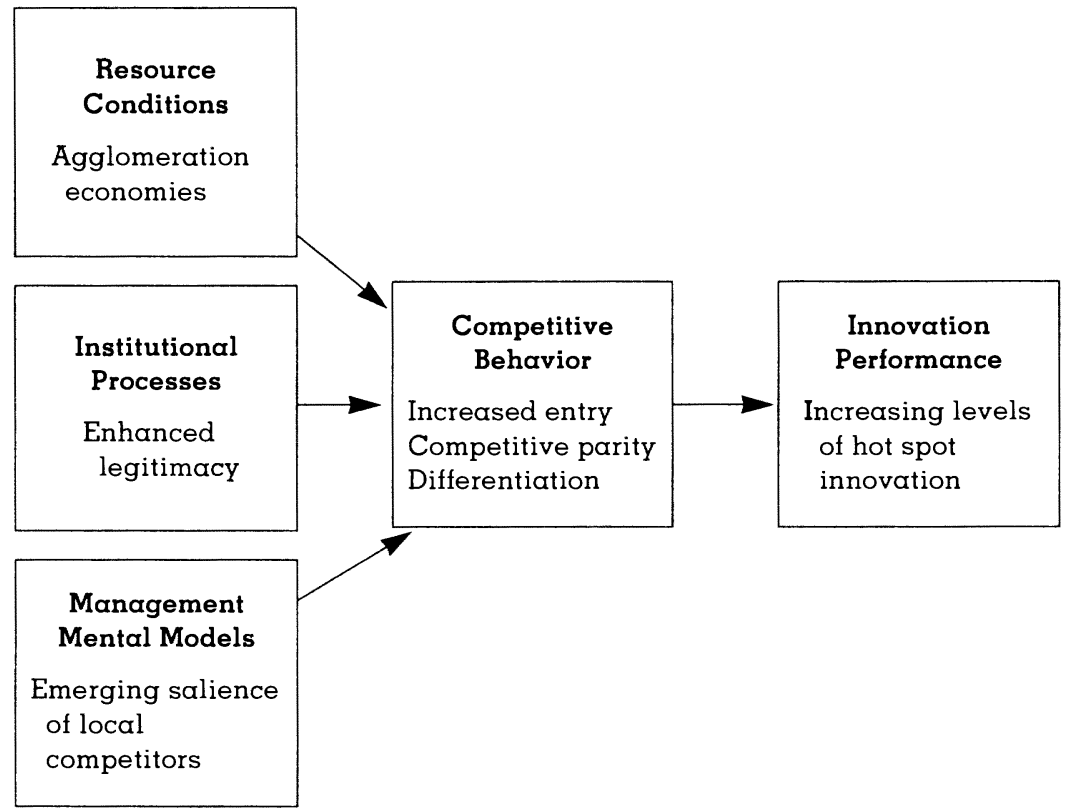

the cluster. As the cluster grows, however, size, congestion, and saturation within the hot spot may begin to "choke off" the agglomeration economies. Diseconomies of agglomeration may occur as the cost of living, real estate prices, and salaries of technical personnel rise (Arthur, 1990; Grove, 1987). The abundance of venture capital may create constant start-ups and a short-term orientation to investments (Grove, 1987). As the overall industry moves through a life cycle, typified by increasing standardization, the requirements for the technical and financial resources (university, venture capital firms) of the hot spot are reduced, which makes other locations relatively more attractive (Melecki, 1985). The economies of agglomeration can be undermined in much the same way that manufacturing facilities that are too large move from economies of scale to diseconomies of scale, and urban areas often grow beyond the ability of the infrastructure to adapt. The first-mover advantages that accrued to the first cluster are gradually eroded as outside competitors gain strength in the population.

Proposition 5: Over time, the agglomeration economies in the hot spot will erode, and the hot spot firms will experience cost economies similar to competitors outside of the hot spot.

\section{Convergence and Managers' Mental Models}

Managers in hot spots face an expanding field of local competitors during the transition from origination to convergence. For reasons 
discussed in Table 2, their access to and awareness of local competitors would grow over time. The ease of social interaction and observation afforded by proximity increases the availability and richness of information on local competitors. Because such information would be considered important and engaging, its effect is likely to be salient (Sullins, 1989). Clustering salient competitor attributes in their mental models allows managers to simplify cognitive complexity while enriching their information about important competitors (Porac et al., 1987; Reger \& Huff, 1993). Managers in hot spot firms, then, use mental models to narrow the focus of competitors and to provide rich information on local competitors.

Mental models based primarily on local competitors will be biased toward those competitors; at the same time they will direct attention away from outside competitors. Consequently, as local competitors increasingly dominate the perceptions of managers in the hot spot, competitors outside of the industry will be subject to less rigorous scrutiny. ${ }^{5}$ This intuition is supported by Porac and colleagues (1987: 74-75), who, in a study of retailers, noted that their "competitive moves will be primarily aimed at countering the tactics of firms within the same [competitive] category rather than firms in categories not scanned. [The competitive] focus of attention [is] locked in by the cognitive structuring effect of the business category so defined."

Researchers in social cognition showed that, in addition to dominating perception, salient stimuli tend to polarize judgments without an individual's awareness of the effects on subsequent judgments (Fiske, 1993; Mullen \& $\mathrm{Hu}, 1988)$. Because managers within hot spot firms are exposed to the same sources of information, it is likely they will form similar perceptions of clustered competitors' capabilities. As a consequence, competitive judgments arising from managers' mental models in hot spots become more homogeneous and reflect less awareness of outside competitors over time. By not updating their mental models of competitors, managers will fail to incorporate information that conflicts with their established perceptions.

As noted previously, managers in firms outside of the hot spot also will simplify their mental models and direct their attention toward salient competitor attributes. However, one key issue distinguishes the nature and effect of simplification of mental models for managers inside and outside the hot spot. In the absence of proximity, managers outside the hot spot will develop their own ways to simplify their mental models based on competitor and market attributes that are most salient to them. One manager may focus on major market shareholders, whereas another may focus on competitors that supply a particular customer segment. In

\footnotetext{
${ }^{5}$ Of course, as inferred from the previous discussion, there are greater opportunities for network interaction with outside competitors in the growing hot spot. More suppliers, customers, professional societies, social organizations, and so on, will be found outside of the cluster in later stages of growth compared to earlier stages of growth. However, these opportunities would be overshadowed by the overall ease with which proximity facilitates social and professional interaction among competing firms in the hot spot.
} 
other words, managers outside the hot spot will be more likely to develop different mental models of competition. Managers inside the hot spot, influenced by the salience of information on local competitors, will tend to develop similar perceptions about competitors. Managers outside the hot spot are less likely to form homogeneous perceptions.

Proposition 6: During the convergence phase, the mental models of strategists within hot spot firms will exhibit biased assessments of competitors' capabilities and place too much emphasis on hot spot competitors and too little emphasis on non-hot spot competitors. Managers outside the hot spot will not exhibit the same bias.

Proposition 7: During the convergence phase, strategists within hot spots will be more homogeneous in their perceptions about competitors and industry opportunities than will managers outside of the hot spot.

\section{Convergence and Institutional Processes}

When the homogeneous mental models shared among hot spot managers are aggregated to the level of firms, the result is what Abrahamson and Fombrun described as a macroculture, the "relatively idiosyncratic, organization-related beliefs that are shared among top managers across organizations" (1994: 730). Abrahamson and Rosenkopf (1993) proposed that interdependent networks of competitors, called collectivities, experience close to full information about the organization processes and innovation capabilities of competitors, which encourages imitation. Zander and Kogut (1995) found that a key determinant of the time to imitation of an innovation is the extent to which knowledge of processes is common among competitors within the industry. Given the high level of awareness among competitors within the hot spot and their tendencies to monitor closely firms that are viewed as direct competitors (Haveman, 1993; Porac \& Thomas, 1990), imitation is likely.

As researchers of interorganizational networks have observed, the collectivity of hot spot firms would be governed by norms of acceptable conduct. These norms would be institutionalized through patterns of social and professional interactions (see Table 2), human resource training and selection, and generally accepted rules of the game that have evolved over time (Porac \& Thomas, 1994). The mental models that capture those organizational forms would be one important component of the collective mindset, or macroculture, embedded within the hot spot (Porac \& Thomas, 1994).

This collective mindset creates the preconditions that make the hot spot firms susceptible to institutional forces that encourage homogeneity. At this point in the evolution of the hot spot, the competitors, suppliers, local communities, labor force, venture capitalists, and research 
community begin to exhibit the structure of an organization field. DiMaggio (1983) described an organization field as involving four elements, all of which are exhibited within hot spots: (a) increased interaction among organizations in the field, (b) emergence of dominant competitors and patterns of coalition, (c) increased information, and (d) mutual awareness of involvement in a common enterprise, or a group identity.

Once the field is created, uncertainty and institutional pressures work to make the organizations more alike. Uncertainty about technologies and markets encourages a pattern of conformity through imitation, known as mimetic isomorphism (DiMaggio \& Powell, 1983). When faced with uncertainty, firms will economize on search costs (Cyert \& March, 1963) and imitate the actions of other organizations (Haveman, 1993). Hot spots, which are often associated with high-technology industries and are, by our definition, fast growing (during the origination phase), experience high levels of technology and market uncertainty. Hot spots, therefore, will likely experience mimetic isomorphism as firms respond to that uncertainty.

The hot spot context is also susceptible to exaggerated forces of coercive isomorphism. Coercive isomorphism occurs when procedures, controls, and structures within the organization field create institutional pressures for conformity (DiMaggio \& Powell, 1983). Within hot spots, the common set of goals, processes, and systems of the suppliers, researchers, and venture capital firms work to create homogeneity. For example, a dominant local supplier may be capable of meeting a particular quality standard; therefore, all local competitors achieve that level of input quality. The venture capital firms expect a certain strategy and plan for funding, so strategies and plans of firms within the cluster begin to take on similar characteristics.

Finally, the hot spot, because of its identity with a particular research university and community, may be susceptible to pressures for normative isomorphism (DiMaggio \& Powell, 1983). If many of the contract researchers and new employees are recruited from the local university and the local competitors, they will tend to define problems and filter information in the same way (DiMaggio \& Powell, 1983).

In the origination phase of industry evolution, the benefits of conformity are legitimacy, stability, access to resources, and the ability to attract skilled personnel (Oliver, 1991), all of which provide competitive advantages to the hot spot firms and contributed to the growth and innovation advantages we proposed for the origination phase. Over time, however, the institutional processes cause firms to fail to exercise full strategic choice (Oliver, 1991) and to be constrained in their ability to change (DiMaggio \& Powell, 1983; Powell, 1991).

Viewed in this way, the strategic myopia associated with competitors' blind spots is a collective process (Abrahamson \& Rosenkopf, 1993). Homogeneity of managers' beliefs within the macroculture leads to similarities in competitive positions, which leads to insularity, sluggishness, and failed attempts to innovate (Abrahamson \& Fombrun, 1994). As described 
by Yates (1984), these outcomes were evident for U.S. automakers during the late 1970s and early 1980s. The complacent and insular "collective Detroit mind" was homogenized by the perception that outside (specifically, Japanese) competitors were essentially nonexistent and posed no threat to U.S. automakers. Despite the consumers' changing preference for small cars, Yates pointed out that

isolated in their Warren and Dearborn enclaves, the American experts continued to delude themselves into thinking that the old verities of the American marketplace would prevail. In their hearts, they believed that the once-sizzling love affair between Detroit and the car buyers of the nation could be rekindled. (1984: 31)

\section{Competitive Behavior and Innovation}

As the hot spot moves through the convergence phase, the economies of agglomeration and the need for legitimacy that drew new firms to the region and provided the cluster with a collective cost and access advantage erode (Proposition 5). Consequently, firms will be no more likely to enter the cluster than to begin business elsewhere. Spin-offs will be no more likely to happen in the cluster than outside of the cluster. In terms of cost structures, resource access, and patterns of competitor entry and exit, the hot spot and the larger industry population will reach parity, and there will be no collective advantage for the cluster. In essence, the patterns of growth for both the cluster and the larger industry population will align.

Proposition 8: In the convergence phase, the hot spot industry subpopulation will stabilize compared to the larger industry population, experiencing similar patterns of entry and exit.

Although entry and exit will stabilize, firms inside and outside of the hot spot will continue to differ in their susceptibility to institutional pressures for isomorphism, as described previously. The transition toward homogeneity, supported by managers' biased mental models and institutional forces that encourage imitative competitive behavior, will lead to a decline in the collective level of innovation coming from the hot spot over time. Competitors outside of the hot spot that are not part of the collectivity will not be part of the dysfunctional macroculture and will be physically separate from the localized sources of isomorphism. The identifiable organization field of the clustered firms will continue to evolve along a parallel but separate trajectory (Powell, 1991) from nonclustered firms.

As the convergence phase is fully realized, the following outcomes can be expected: (a) firms will not distinguish among local competitors, thereby homogenizing perceptions of strategic options and their strategic actions (Reger \& Huff, 1993); (b) biased cognitive assessments and insularity will perpetuate homogeneous macrocultures (Abrahamson \& Fombrun, 
1994), (c) institutional forces will encourage homogeneity and inertia (DiMaggio \& Powell, 1983), (d) the deep structure, despite changes in competitor and market conditions, will perpetuate convergence, increase inertia, and decrease competitive vigilance (Tushman \& Romanelli, 1985); (e) managers will perpetuate the mental model, which becomes more distorted over time, and create competitive blind spots (Porter, 1980); and (f) firms will create fewer innovations because of the homogeneity, inertia, and dysfunctional macroculture.

Proposition 9: During the convergence phase, hot spot firms will exhibit higher levels of organizational inertia and imitative competitive behavior compared to outside competitors.

Proposition 10: During the convergence phase, the collective level of innovation emanating from the hot spot will decrease over time.

The resource conditions, institutional processes, and mental models influencing competitive behavior and innovation in the convergence phase are shown in Figure 4.

\section{FIRM-LEVEL REORIENTATION WITHIN FORMER HOT SPOTS}

As we stated previously, convergence of clustered firms within a larger industry population can continue indefinitely. Once the relative rates of

FIGURE 4

Key Forces Affecting the Evolution of Hot Spots During the Convergence Phase

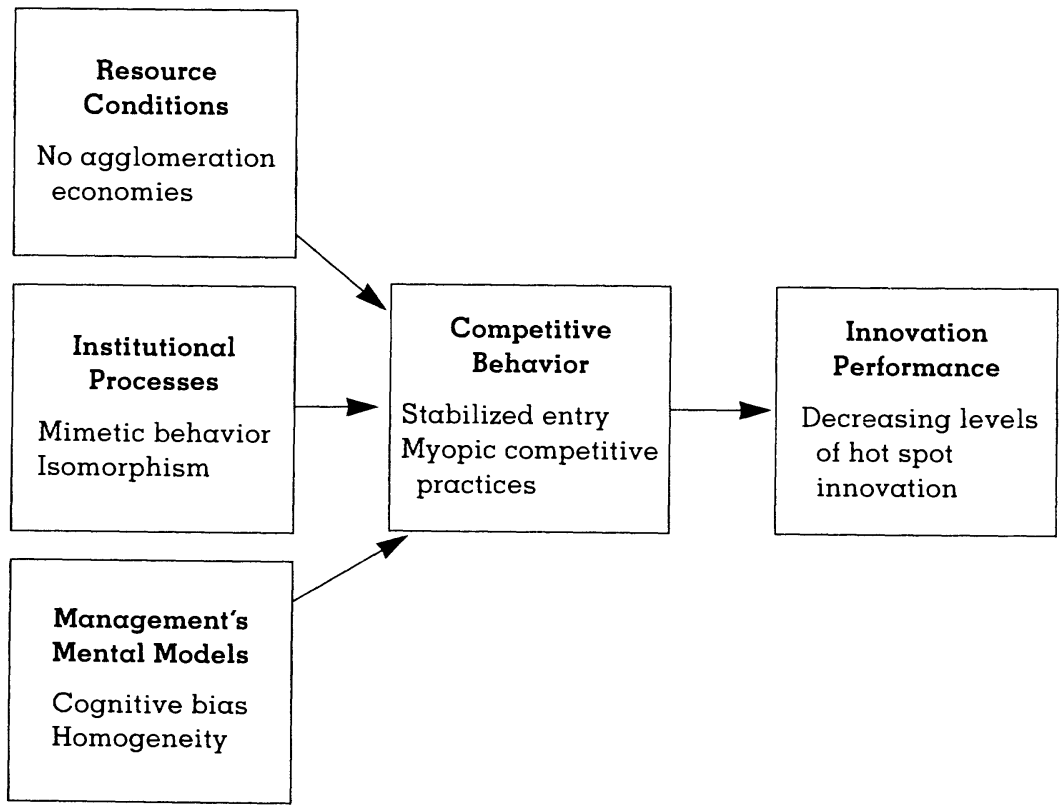


growth and innovation stabilize for firms inside and outside of hot spots, the cluster will no longer fulfill the definition of a hot spot in terms of growth, but it will continue to survive as a tight cluster of competitors. The Dalton, Georgia, cluster of carpet makers and the Hickory, North Carolina, cluster of furniture makers, for example, have existed for decades, but they are neither more faster growing nor more innovative as a group than are their nonclustered competitors.

The punctuated equilibrium literature and discussions of cognitive bias in industry assessment support the notion that periods of crisis or shock often precede fundamental changes in the deep structure of firms and their realignment of perceptions with actuality (Gersick, 1991; Tushman \& Romanelli, 1985; Zajac \& Bazerman, 1991). Following a long period of convergence, firms are susceptible to a significant environmental jolt, such as a technological shift, emergence of new competitor groups and methods, or significant changes in market demand. Environmental jolts will likely overwhelm the adaptive processes of organizations (Meyer, Brooks, \& Goes, 1990) and initiate, for some firms, a period of fundamental reorientation (Tushman \& Romanelli, 1985). In the following sections, we argue that clustered and nonclustered competitors differ in their ability to anticipate and then react to industrywide jolts. Although some firms may reorient themselves successfully, and the region may continue to grow through other industries, it is likely the region will no longer be a center of innovative activity for the former hot spot industry.

\section{Environmental Jolts}

Environmental jolts, or Schumpeterian shocks (Barney, 1991; Schumpeter, 1934), tend to occur in three phases: (a) an anticipatory phase that includes perceptible warning signals, (b) a responsive phase when the primary impacts are absorbed, and (c) a readjustment phase (Meyer, 1982). As described by Meyer (1982), environmental jolts rarely threaten the survival of organizations that are aligned with their environments.

An organization's ability to anticipate a shock is determined by the aggressiveness and accuracy of its environmental-scanning activities (Meyer, 1982). As established in our previous discussions, clustered firms in the convergence phase exhibit the characteristics of a macroculture, and they will conduct limited and biased searches for competitive information (Abrahamson \& Fombrun, 1994). Although firms outside of the hot spot may suffer from limited environmental-scanning activities and may miss the signals of an impending jolt, for them, such widespread myopia is unlikely to exist. Therefore, clustered firms are more likely than nonclustered firms to miss the signals that would warn them of an impending jolt.

An organization's ability to respond to a shock is influenced by the interdependencies that are institutionalized through its structure and processes (Meyer, 1982). As previously described, geographically clustered firms often exhibit networks of interdependencies with local competitors, research institutions, suppliers, and associations, which originally enhanced legiti- 
macy and ensured agglomeration economies (Scott, 1989). The networks of interdependencies that were a source of strength in the origination phase become sources of inertia and inflexibility (Abrahamson \& Fombrun, 1994) during a jolt. Consequently, clustered firms will be slower to react to a jolt than will their nonclustered competitors.
Proposition 11: Clustered competitors will be slower to recognize and respond to an industrywide environmen- tal jolt than will competitors outside of the hot spot.

\section{Implications for Firm-Level Reorientation}

A reorientation period involves a short burst of discontinuous change in which a firm's strategy, structure, power distributions, organization culture, and control systems are realigned (Gersick, 1991; Tushman \& Romanelli, 1985). Reorientations may involve a significant alteration of strategy, structure, and systems (Romanelli \& Tushman, 1994) and, for more entrenched firms, an even more substantial re-creation of core values and mental models (Gersick, 1991; Tushman \& Romanelli, 1985). To dismantle their deep structures (Gersick, 1991) so that they can consider alternatives outside of their self-imposed boundaries, organizations must change both their basic premises and values about the nature of competition (i.e., mental models) and the interrelationships and systems within which they operate (Tushman \& Romanelli, 1985). Given the sweeping scope of change required for reorientations, these will likely involve change and development processes at many organizational levels: individual strategists, firms, the collectivity of competitors within the former hot spot, and the larger organizational field involving suppliers and communities (Van de Ven \& Poole, 1995).

Realigning managers' mental models. The mental models described for the convergence phase provide a useful starting point for explaining whether managers are well prepared to deal effectively with environmental jolts. According to research in social cognition, once mental models are formed they tend to persist, even in the face of contrary evidence (Fiske \& Taylor, 1991). In addition to individuals, established mental models can be common to a social group such as managers (McKaskey, 1982). Historically salient material persists in managers' memories and continues to influence what they interpret as salient in current situations (Kiesler \& Sproull, 1982). For example, when making judgments about current problems, managers often use mental models to "fill in" information that stems from a great deal of experience with prior problems (Kiesler \& Sproull, 1982: 560). In sum, as these managers access new information about competitors, they rely on a class of anachronistic mental models, framed in an environment that no longer exists (Porac \& Thomas, 1990).

If managers use salient information about local competitors to evaluate outside competitors, they will ignore or misinterpret the organizational crisis ushered in by an environmental jolt. In the words of Yates, "Detroit was convinced that American consumers insisted on instant gratification, 
ignoring the example of thousands of devoted Honda buyers who were patiently waiting six months or more for their small silver chariots" (1984: 62-63).

Proposition 12: Compared to strategists in firms outside of the hot spot, the mental models of strategists in firms inside the hot spot will exhibit higher levels of cognitive inertia and entrenchment that inhibit initiation of a firmlevel reorientation following an environmental jolt.

Environmental jolts rock the very foundation of an organization, leaving fissures in the deep structure and sometimes causing the eventual collapse of the organization. The strategic action or inaction of top management will determine how strong or how weak the remaining organizational foundation will be. Managers who anticipate the need for reorientation and install radical changes have been associated with more successful realignment, whereas managers who are either unable to adapt or refuse to adapt are often replaced (Tushman, Newman, \& Romanelli, 1986). The research results imply that the environmental jolt or crisis worked to alter strategists' dysfunctional mental models of competitors, so that they could recognize the need for change and reorientation. Thus, mental models become realigned with a new industry environment. Organizations that fail to overcome cognitive inertia and realign their mental models are not likely to survive.

Proposition 13: Within those former hot spot firms that initiate a radical response to the environmental jolt, the mental models of strategists will be realigned (through replacement or change) with new assumptions about competitors, markets, and industry boundaries.

Resisting institutional forces. For individual firms, the crisis of failed innovations and declining performance provides the impetus for change, but it does not automatically create change. The effects of institutional forces, distorted mental models, and the resulting deep structure may run too deep. As Gersick noted, "As long as events occur against a backdrop of the same deep structure, they are treated or interpreted in ways that preserve the system's inertia and, therefore, incremental solutions are sought. The handwriting on the wall cannot be read" (1991: 22).

When faced with an environmental jolt, firms that have altered their mental models (through changes in managers' mental models or replacement of existing managers) and can recognize the dangers of conformity are likely to begin to resist institutional processes. When organizations perceive that the value of compliance with institutional norms is low and that those norms are not compatible with new organizational goals, the organization will dismiss or ignore the norms (Oliver, 1991). For example, a firm in the former hot spot may initiate a marketing or productdevelopment strategy that departs from convention. In some cases, organizations may actively challenge institutional norms (Oliver, 1991). For 
example, a firm may confront suppliers or labor leaders in an effort to change traditional norms of behavior, or it may relocate out of the region.

Some firms will not shed their old mental models of competition and innovation. Consequently, those firms will not recognize the need for radical change, will not resist institutional pressures for homogeneity, and will likely not survive the environmental jolt. They will initiate only those incremental solutions allowed within the old cognitive framework (Gersick, 1991). Fast-paced, radical change of structure, strategy, practices, methods, and beliefs is more likely to result in improved firm performance compared to incremental adaptive changes (Miller \& Friesen, 1982; Romanelli \& Tushman, 1994; Virany, Tushman, \& Romanelli, 1992). When the incremental changes fail to create significant improvements in performance, the firms will be unable to initiate the type of fundamental restructuring required to dismantle their old deep structures.

Proposition 14: Only those firms that undergo a significant change in their organization's structure and processes will survive a hot spot failure.

\section{Implications for the Former Hot Spot}

Even if firms change significantly, it is unlikely the hot spot will survive. The resource base and interrelationships of the geographical area may have little value after the jolt, particularly if new suppliers or technologies are needed for such a change. One might argue that the vulnerability of the hot spot would decrease as some local competitors develop effective approaches that ultimately could be adopted by others. Unfortunately, it is the very nature of geographically circumscribed competition-the continuous benchmarking of other local competitors and the networks of interdependencies - that virtually locks all managers into a similar, parochial view of competition. Consequently, opportunities for interorganizational learning about outside competitors are inadequate. By collectively benchmarking local competitors who had similar problems, managers in minicomputer firms located on Route 128 could not respond to both the technological and market shifts for personal computers. Guided by anachronistic mental models that persisted under conditions of local competition, cognitive reorientation in this hot spot was stifled.

Two theoretical, philosophical approaches exist for managing the regional implications of a hot spot failure: incubation and intervention. The incubation view is consistent with organizational ecology and the natural evolution of populations. The intervention approach is more compatible with the interests of regional economists, and it involves proactive efforts to sustain and support existing hot spots. These two views are discussed in the following paragraphs.

Incubation. A hot spot may be viewed as an incubator of start-ups and spin-offs during the origination phase of evolution. When hot spot firms have stretched the incubation capability of the region, the ties to the hot spot are no longer needed. Because the advantages of agglomera- 
tion and cooperation within the hot spot were largely undermined at the later part of the convergence phase, a firm's survival will be dependent on firm-level resources and capabilities rather than agglomeration benefits.

According to the incubator view, firms seek their own strategic responses that suit their circumstances, without any involvement by the community or regional policy makers. A natural evolution of the hot spot is likely to occur, some firms will change firm-level reorientations, and an even smaller subset of those firms will achieve improved performance. As a result of the natural progression of change, some firms will fail and other firms will thrive within the former hot spot region. New firms, and possibly new hot spots, will be born in new locations, and some firms from the former hot spot will relocate out of the region, as they all seek new sites of agglomeration economies and supportive infrastructure. The cluster will no longer represent an industry-specific hot spot.

These arguments are supported in part by the views of organization ecologists. According to these researchers, when population inertia is great, significant changes and renewal within the population will come primarily through the birth and death of organizations (Hannan \& Carroll, 1992; Hannan \& Freeman, 1989). Because firms in the former hot spot will not be developing innovations that have value in the marketplace, the size of the former hot spot will shrink, and more efficient firms will prevail (Zammuto, 1988). The dearth of innovations within the former hot spot will create opportunities for new and existing firms within the larger industry population (Zammuto, 1988).

Why will few firms from the former hot spot thrive? During the long process of hot spot convergence, industry competitors outside of the hot spot will have developed innovations and organizational efficiencies that were instrumental in isolating the hot spot in the first place. Even if firms in former hot spots attempt to formulate strategies that address inefficiency and stagnation, they would lag far behind those outside competitors. The local resource base may no longer provide value. Furthermore, the homogeneity or misdirected innovative efforts and competitive blind spots of firms inside the hot spot suggest their basic inability to deal with inefficiency or technical stagnation or both. Firms within the former hot spot would be playing catch-up with other industry competitors, and many of them would not have the organizational wherewithal to adapt.

During the convergence phase, hot spot firms evolved while being isolated from industry trends and competitive events, which exacerbated their existence as a subpopulation within the larger industry population. As a subpopulation evolves separately from the total population, it will show less fit with the environment and "will tend to be eliminated. The stable equilibrium will then contain only one population which can be said to be isomorphic to the environment" (Hannan \& Freeman, 1989: 934).

This evolutionary destruction has been observed in several hot spots. In some cases, the entire center of gravity for industry innovation shifts elsewhere. Although individual firms will survive and thrive, the former 
hot spot region will lose its identity. It is likely that the community and region will suffer declines in employment growth, new business formations, and economic vitality, as was experienced in Detroit, on Boston's Route 128, and in Silicon Valley.

Proposition 15: Following a jolt, the former hot spot will experience disproportionate losses in growth and innovation compared to competitors outside of the hot spot.

Intervention. In regional science and economic geography, a primary concern of policy makers and communities is to prevent deterioration of the hot spot. They would attempt to restore the hot spot to its original level of growth and innovation by re-creating the conditions of the origination phase. Scott (1992) noted that, in theory, declining hot spots might be revived by local economic-development policies designed to stimulate R\&D, skills training for the local labor force, business support services to guide reorientation and restructuring efforts, public sponsorship of interfirm networks to encourage new joint ventures and alliances, and effective management of the local infrastructure, through land-use planning, tax policies, and development of science parks, so that the economies of agglomeration can be restored.

Such efforts do not ensure successful restoration of a hot spot. It is difficult to create the conditions to spawn a new hot spot, and it would be just as difficult to re-create or sustain a hot spot (Scott, 1992). Collective efforts by policy makers and communities to guide hot spot behavior may represent yet another source of institutional pressure designed to isolate the hot spot from real competitive forces and to encourage sameness among hot spot competitors.

The resource conditions, institutional processes, and mental models influencing competitive behavior and innovation following an environmental jolt are shown in Figure 5.

\section{CONCLUSION}

The model of hot spots developed in this article evokes theories from the levels of individual manager, firm, collectivity, and industry to show how geographically clustered competition can affect innovation over time. To explain the interplay between levels, our framework juxtaposes schools of thought in a common setting and, at the same time, preserves theoretical pluralism (Astley \& Van de Ven, 1983). Specifically, we propose complementary explanations of multilevel phenomena to show how geographic clustering of competing firms affects innovation over time. Rather than assume, as have some theorists, that processes of convergence and reorientation in the structure of an industry simply unfold (Meyer et al., 1990), we specify mechanisms for such changes.

The theory of innovation in hot spots advanced in this article extends punctuated equilibrium theory because evolutionary competitive selection and managerial enactment are reviewed as simultaneous, rather than 
FIGURE 5

Key Forces Affecting the Evolution of Hot Spots Following a Jolt

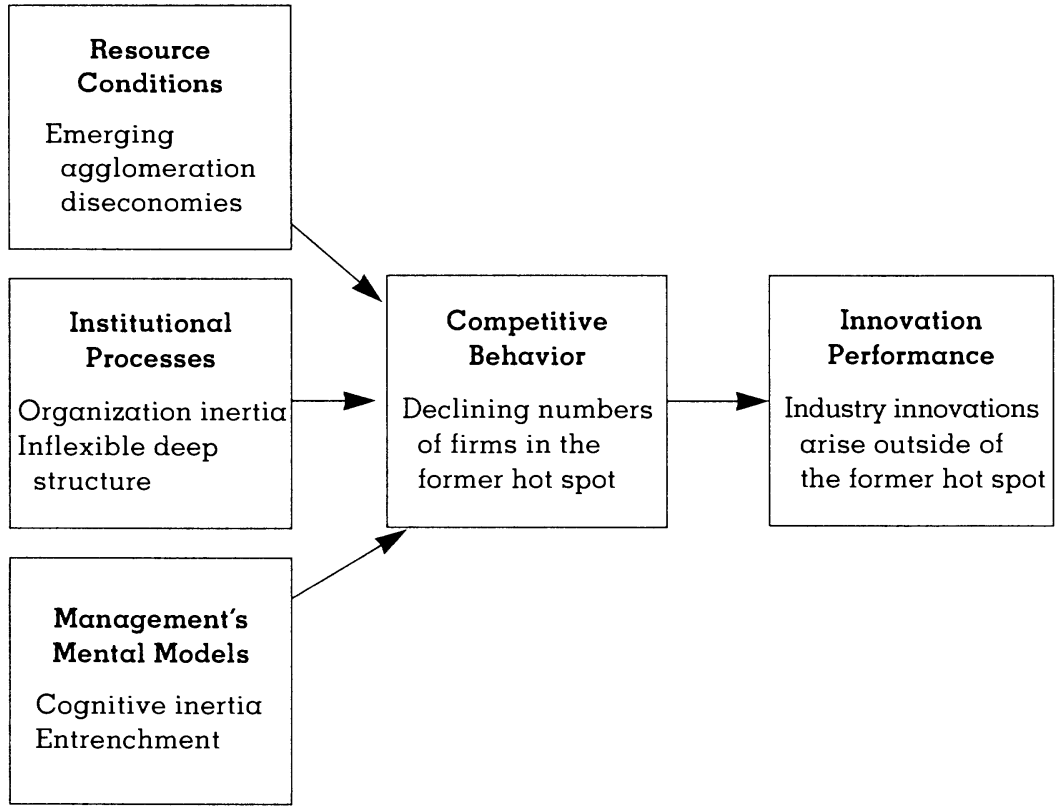

isolated, change processes (Van de Ven \& Poole, 1995). Placing organizations in the context of hot spots has implications for the way organization ecologists perceive how exogenous changes redefine viable niches and affect the emergence of new organizational forms. Moreover, by incorporating research from economic geography, we have responded to Baum and Mezias (1992), who advised that studies at the population level should incorporate economic models of spatial competition.

More generally, the framework presented here links three areas of management research that some scholars view as key areas for future work: (a) competitive dynamics viewed from different perspectives, (b) industry transformations, and (c) dominant logic (Prahalad \& Hamel, 1994). Through this framework, we consider competitive dynamics using a different unit of analysis that could be applied to studies of strategic groups and other subpopulations. Also, we consider the pacing and processes of industry transformation by focusing on the dynamics between firms inside and outside of hot spots. Finally, we link the mental models of managers to competitive dynamics and industry transformation. The next sections explain how the conceptual framework may be used both to guide conceptual and empirical research and to address policy issues.

\section{Implications For Theory and Research}

Our model of hot spots provides three avenues for future research. First, and most basic, the model invites theory-building research directed 
toward broadening and deepening explanations of the events giving rise to hot spots: What specific cooperative arrangements in clusters of competing firms would make hot spots more likely, and how do they compare with such arrangements found among outside competitors? To what extent are the clusters that ultimately become hot spots formed through random versus predictable processes? Researchers of system dynamics using mathematical analysis, for example, could explore differences between some of the variables used to compare hot spots and outside industry competitors. In particular, nonlinear models and chaotic processes may offer better explanations of dynamic relationships (Van de Ven \& Poole, 1995).

Organization researchers must also reassess the generalizability of experimental contexts in social cognition to better specify variables in mental models, especially those most closely associated with the formation of competitor clusters: What contextual variables would help explain systematic differences in the formation of mental models in clustered and nonclustered competing firms? When and how do specific types of information become salient in a manager's mental model of competitors? Do other features, such as the vividness of competitors, contribute to the salience of attributes?

We have drawn from the institutional viewpoint to explain clustering of competing firms in the same industry. We proposed that managers' mental models of competitors become similar, contributing to a macroculture, which, in turn, leads to homogeneity and inertia within the cluster of local competitors. Greater attention to modeling causal links between cognitive and institutional processes is required. For example, institutional theorists could benefit from recognizing the contribution that individual actors can make to innovation processes (Jennings \& Zandberger, 1995).

In addition to descriptive research on hot spots, there is a need for prescriptive models that address successful reorientation among firms competing in hot spots. Although there is a need for greater empirical evidence before such models can be developed, the ideas presented on hot spots lead naturally to several research topics: Can firms initiate organizational-development efforts that modify organizational culture and lead to restructuring activities that refocus the firms' competitive priorities? Are successful reorientations more likely when top managers are hired from outside the cluster and existing managers are replaced prior to an environmental jolt (Virany et al., 1992)? Can new suppliers, new sources of technical and skilled labor, or relocation out of the region dismantle institutional pressures on a firm to conform?

Clearly, there are other ways to extend conceptual research on organizational change that can inform the understanding of innovation. For example, in recent work on organizational change processes, Van de Ven and Poole (1995) posited that different generative mechanisms of change can operate simultaneously. Their typology repositions punctuated equilibrium as the interplay, rather than the mutually exclusive operation, of 
time-dependent change. Such change is driven in opposing directions by competitive selection (convergence) and purposeful managerial enactment (reorientation). Future work on the organization level in hot spots could benefit from this typology's conceptual clarity and orderly presentation of complex issues.

The second avenue for future research suggested by our model of hot spots is theory testing within geographically determined boundaries. By studying managers and firms, strategy researchers could address questions concerning the definition and evolution of strategic groups. Do competitors in hot spots form well-defined, "natural" strategic groups that are more accurate representations of strategic groups formed on a tautological basis (Barney \& Hoskisson, 1990)? What is the relationship between "competitive groups" (firms that compete against one another) and "strategic groups" (firms that compete using similar strategies) (Reger \& Huff, 1993: 118)? By applying techniques used by Porac and his colleagues (1987, 1989, 1994), researchers could explore the following question: What roles do managers' mental models play in the formation of strategic groups? Can greater insight be gained about the relationships between evolution of strategic groups and evolution of industries and the nature of mobility barriers (McGee \& Thomas, 1986)? Researchers also could study the link between managers' mental models of competitors and homogeneity in innovation strategies of firms in hot spots (Abrahamson \& Fombrun, 1994; Prahalad \& Bettis, 1986; Spender, 1989).

Perhaps by adapting entropy measures of density developed by economic geographers, organization ecologists could get a true picture of competitive interactions between populations and subpopulations (Hannan \& Carroll, 1992). One might construct indicators of institutionalization in innovation strategies over time using methods proposed by Abrahamson and Rosenkopf (1993) to evaluate bandwagon effects across clustered competitors. Cumulated over time, interdisciplinary empirical findings may allow researchers to answer long-standing questions. Because firms in hot spots operate in predominantly technical environments (Meyer \& Scott, 1983), would one expect the competitive pressures espoused by organizational ecologists to better predict a decline in innovation over time compared to the various forms of institutional isomorphism (cf. DiMaggio \& Powell, 1983; Scott, 1991)? In contrast, would the integration of organization ecology and institutional theory fortify researchers' interpretations of processes that occur in hot spots over time? Finally, investigators could conduct research on inertia in firms inside hot spots. Proposed measures of inertia (Gresov, Haveman, \& Oliva, 1993) may prove useful in this case.

The third and final avenue of research is in response to some of the difficulties inherent in studying hot spots. Such difficulties include determining mental models of strategists, agglomeration economies, and institutional forces over time. A promising approach might include multiple parallel case studies (Eisenhardt, 1989; Yin, 1984), which incorporate 
longitudinal data collection for different hot spots as they move through phases at different paces. Through multiple case studies, researchers would use the same protocol for collecting data and assessing patterns over time within each industry unit of analysis (Yin, 1984). The result of such studies may provide useful information for managers and policy makers.

\section{Policy Implications}

Once a super nova for state-of-the-art innovation, the hot spot quickly becomes an industry black hole. The absorbing irony is that some of the factors drawing firms to hot spots are the same factors that ultimately cause their demise. Because of their potential growth in numbers, hot spots are likely to become increasingly important policy issues. At the heart of these issues, policy makers will seek prescriptive strategies that attempt to reduce the susceptibility of hot spots and prevent dysfunctional responses to environmental jolts. Whereas the framework developed here does not prescribe policies, it does offer policy makers a view of the evolutionary process and its consequences.

The central question in this context is whether policy intervention can avert economic losses and return firms to high levels of innovative activity following an environmental jolt. Future research efforts guided by the conceptual framework and directed toward specific policy makers' interests may prove useful here. Among these interests, policy makers may want to understand the processes that contribute to dysfunctional patterns of innovation. Researchers could help by identifying factors that enable some firms to sidestep dysfunctional institutional pressures in the hot spot, such as participating in trade associations and making strategic alliances with firms outside of the hot spot. Policy makers might then be able to provide incentives that encourage firms to form external alliances. When researchers identify regions as hot spots, policy makers may be motivated to mitigate potential economic devastation by developing policies that attract new industries to the region. Implicit in our propositions concerning the reorientation phase, policy intervention can do little to restore competitive innovation for hot spots following a jolt. However, research based on a theory of hot spots may assist policy makers in developing informed regional economic policy.

\section{REFERENCES}

Abrahamson, E., \& Rosenkopf, L. 1993. Institutional and competitive bandwagons: Using mathematical modeling as a tool to explore innovation diffusion. Academy of Management Review, 18: 487-517.

Abrahamson, E., \& Fombrun, C. 1994. Macrocultures: Determinants and consequences. Academy of Management Review, 19: 728-755.

Aldrich, H. E., \& Fiol, C. M. 1994. Fools rush in? The institutional context of industry creation. Academy of Management Review, 19: 645-670. 
Angel, D. P. 1989. The labor market for engineers in the U.S. semiconductor industry. Economic Geography, 65: 99-112.

Arthur, W. 1990. Silicon Valley locational clusters: When do increasing returns imply monopoly? Mathematical Social Sciences, 19: 235-251.

Astley, G. W., \& Van de Ven, A. H. 1983. Central perspectives and debates in organization theory. Administrative Science Quarterly, 28: 245-273.

Bania, N., Calkins, L. N., \& Dalenberg, D. R. 1992. The effects of regional science and technology policy on the geographic distribution of industrial R\&D laboratories. Journal of Regional Science, 32: 209-228.

Barney, J. B. 1991. Firm resources and sustained competitive advantage. Journal of Management, 17: 99-120.

Barney, J. B., \& Hoskisson, R.E. 1990. Strategic groups: Untested assertions and research proposals. Managerial and Decision Economics, 11: 187-198.

Baum, J. A., \& Mezias, S. J. 1992. Localized competition and organizational failure in the Manhattan hotel industry. Administrative Science Quarterly, 37: 580-604.

Business Week. (1992). Hot spots: America's new growth regions are blossoming despite the slump. October 19: 80-88.

Carroll, G. 1993. A sociological view on why firms differ. Strategic Management Journal, 14: 237-249.

Cyert, R. M., \& March, J. H. 1963. A behavioral theory of the firm. Englewood Cliffs, NJ: Prentice Hall.

Damanpour, F. 1991. Organizational innovation: A meta-analysis of effects of determinants and moderators. Academy of Management Journal, 34: 555-590.

DeNoble, A., \& Galbraith, C. 1992. Competitive strategy and high technology regional/site location decisions: A cross-country study of Mexican and U.S. electronic component firms Journal of High Technology Management Research, 3: 19-37.

DiMaggio, P. J. 1983. State expansion and organizational fields. In R. H. Hall \& R. E. Quinn (Eds.), Organization theory and public policy: 147-16l. Beverly Hills, CA: Sage.

DiMaggio, P. J., \& Powell, W. W. 1983. The iron cage revisited: Institutional isomorphism and collective rationality in organizational fields. American Sociological Review, 48: 147-160.

Eisenhardt, K. M. 1989. Making fast strategic decisions in high-velocity environments. Academy of Management Journal, 32: 543-576.

Fiske, S. T. 1993. Social cognition and social perception. In Annual review of psychology. 44: 155-194.

Fiske, S. T., \& Taylor, S. E. 1991. Social cognition. New York: McGraw-Hill.

Florida, R., \& Kenney, M. 1990. Silicon valley and Route 128 won't save us. California Management Review, 33(1): 68-85.

Gersick, C. J. 1991. Revolutionary change theories: A multilevel exploration of the punctuated equilibrium paradigm. Academy of Management Review, 16: 10-37.

Grant, R. M. 1991. The resource-based theory of competitive advantage: Implications for strategy formulation. California Management Review, 32(3): 114-135.

Gresov, H. A., Haveman, H., \& Oliva, T. A. 1993. Organizational design, inertia, and the dynamics of competitive response. Organization Science, 4: 181-208.

Gripsrud, G., \& Gronhaug, K. 1985. Strategy and structure in grocery retailing: A sociometric approach. Journal of Industrial Economics, 33: 339-347.

Grove, A. 1987. The future of Silicon Valley. California Management Review, 29(3): 154-160. 
Gupta, U. 1992. Venture capitalists rediscover allure of the Midwest. Wall Street Journal, November 27: B2.

Hannan, M., \& Carroll, G. 1992. Dynamics of organizational populations: Density, legitimation, and competition. New York: Oxford University Press.

Hannan, M., \& Freeman, G. 1988. The population ecology of organizations. American Journal of Sociology, 5: 929-940.

Hannan, M., \& Freeman, G. 1989. Organizational ecology. Cambridge, MA: Harvard University Press.

Haug, P. 1991. Regional formation of high-technology service industries: The software in Washington state. Environment and Planning, 23: 869-884.

Haveman, H. 1993. Follow the leader: Mimetic isomorphism and entry into new markets. Administrative Science Quarterly, 38: 593-627.

Huff, A. S. 1982. Industry influences on strategy reformulation. Strategic Management Journal, 3: $119-131$.

Jennings, P. D., \& Zandberger, P. A. 1995. Ecologically sustainable organizations: An institutional approach. Academy of Management Review, 20: 1015-1052.

Kiesler, S., \& Sproull, L. 1982. Managerial response to changing environments: Perspectives on problem sensing from social cognition. Administrative Science Quarterly, 27: 548-570.

Lomi, A. 1995. The population ecology of organizational founding: Location dependence and unobserved heterogeneity. Administrative Science Quarterly, 40: 111-144.

Maarten de Vet, J., \& Scott, A. J. 1992. The southern Californian medical device industry: Innovation, new firm formation, and location. Research Policy, 21: 145-161.

Mahoney, J. T., \& Pandian, J.R. 1992. The resource-based view within the conversation of strategic management. Strategic Management Journal, 13: 363-380.

Markusen, A., Hall, P., \& Glasmeier, A. 1986. High-tech America: The what, how, and why of the sunrise industries. Boston: Allen \& Irwin.

McCaskey, M. 1982. The executive challenge: Managing change and ambiguity. Boston: Pitman.

McGee, J., \& Thomas, H. 1986. Strategic groups: Theory, research, and taxonomy. Strategic Management Journal, 7: 14l-160.

Melecki, E. J. 1985. Industrial location and corporate organization in high-tech industries. Economic Geography, 61: 345-369.

Meyer, A. 1982. Adapting to environmental jolts. Administrative Science Quarterly, 27: 515-537.

Meyer, A., Brooks, G., \& Goes, J. 1990. Environmental jolts and industry revolutions: Organizational responses to discontinuous change. Strategic Management Journal, 11: 93-110.

Meyer, J. W., \& Scott, W. R., 1983. Organizational environments: Ritual and reality. Beverly Hills, CA: Sage.

Miller, D., \& Friesen, P. H. 1982. Structural change and performance: Quantum vs. piecemealincremental approaches. Academy of Management Journal, 25: 867-892.

Mullen, B., \& Hu, L. 1988. Social projection as a function of cognitive mechanisms: Two metaanalytic integrations. British Journal of Social Psychology, 27: 333-356.

Nelson, R. R., \& Winter, S. G. 1982. An evolutionary theory of economic change. Cambridge, MA: Harvard University Press.

Nisbett, R., \& Ross, L. 1980. Human inference: Strategies and shortcomings of social judgment. Englewood Cliffs, NJ: Prentice Hall.

Nohria, N., \& Eccles, R. 1992. Face-to-face: Making organizations work. In N. Nohria \& R. Eccles (Eds.), Networks and organizations: Structure, form, and action: 288-308. Cambridge, MA: Harvard Business School Press. 
Oliver, C. 1991. Strategic responses to institutional processes. Academy of Management Review, 16: 145-179.

Porac, J., \& Thomas, H. 1990. Taxonomic mental models in competitor definition. Academy of Management Review, 15: 224-240.

Porac, J., \& Thomas, H. 1994. Cognitive categorization and subjective rivalry among retailers in a small city. Journal of Applied Psychology, 69: 54-66.

Porac, J., Thomas, H., \& Baden-Fuller, C. 1989. Competitive groups as cognitive communities: The case of Scottish knitwear manufacturers. Journal of Management Studies, 26: 397-416.

Porac, J., Thomas, H., \& Emme, B. 1987. Understanding strategists' mental models of competition. In G. Johnson (Ed.), Business strategy and retailing: 59-79. New York: Wiley.

Porter, M. 1980. Competitive strategy. New York: Free Press.

Porter, M. 1990. The competitive advantage of nations. New York: Free Press.

Powell, W. W. 1991. Expanding the scope of institutional analysis: In W. W. Powell (Ed.), The new institutionalism in organizational analysis: 183-203. Chicago: University of Chicago Press.

Prahalad, C. K., \& Bettis, R. A. 1986. The dominant logic: A new linkage between diversity and performance. Strategic Management Journal, 7: 485-501.

Prahalad, C. K., \& Hamel, G. 1994. Strategy as a field of study: Why search for a new paradigm? Strategic Management Journal, 15: 5-16 [special winter issue].

Rauch, J. E. 1993. Does history matter only when it matters little? The case of city-industry location. Quarterly Journal of Economics, 108: 843-867.

Rees, J., \& Stafford, H. A. 1986. Theories of regional growth and industrial location: Their relevance for understanding high-tech complexes. In J. Rees (Ed.), Technology, regions, and policy: 23-50. Totowa, NJ: Rowan \& Littlefield.

Reger, R., \& Huff, A. 1993. Strategic groups: A cognitive perspective. Strategic Management Journal, 14: 103-124.

Romanelli, E., \& Tushman, M. L. 1994. Organizational transformation as punctuated equilibrium: An empirical test. Academy of Management Journal, 37: 1141-1166.

Saxenian, A. 1994. Culture and competition in Silicon Valley and Route 128. Cambridge, MA: Harvard University Press.

Schumpeter, J. A. 1934. The theory of economic development: An inquiry into profits, capital, interest and the business cycle. Cambridge. MA: Harvard University Press.

Scott, A. J. 1989. New industrial spaces: Flexible production organization and regional development in North America and Western Europe. London: Pion, Ltd.

Scott, A. J. 1992. The Roepke lecture in economic geography: The collective order of flexible production agglomerations: Lessons for local economic development policy and strategic choice. Economic Geography, 68: 219-233.

Scott, W. R. 1991. Unpacking institutional arguments. In W. W. Powell \& P. J. DiMaggio (Eds.), The new institutionalism in organizational analysis: 164-182. Chicago: University of Chicago Press.

Singh, J. V., Tucker, D. J., \& House, R. J. 1986. Organization legitimacy and the liability of newness. Administrative Science Quarterly, 31: 171-193.

Smith, K. G., \& Grimm, C. M. 1991. A communication-information model of response thinking. Journal of Management, 17: 5-24.

Spender, J. C. 1989. Industry recipes: The nature and source of managerial judgements. Oxford, England: Basil Blackwell. 
Suchman, M. C. 1995. Managing legitimacy: Strategic and institutional approaches. Academy of Management Review, 20: 571-610.

Sullins, E. S. 1989. Perceptual salience as a function of nonverbal expressiveness. Personality and Social Psychology Bulletin, 15: 584-595.

Suskind, R. 1992. Boston's high-tech belt, Route 128, once its pride, now chokes recovery. Wall Street Journal, August 19: A6.

Tushman, M. L., Newman, W. H., \& Romanelli, E. 1986. Convergence and upheaval: Managing the unsteady pace of organizational evolution. California Management Review, 29(1): $1-16$.

Tushman, M. L., \& Romanelli, E. 1985. Organizational evolution: A metamorphosis model of convergence and reorientation. In L. L. Cummings \& B. M. Staw (Eds.), Research in organizational behavior, vol. 7: 171-222. Greenwich, CT: JAI Press.

Tversky, A., \& Kahneman, D. 1973. Availability: A heuristic for judging frequency and probability. Cognitive Psychology, 4: 207-232.

Van de Ven, A. H. 1986. Central problems in the management of innovation. Management Science, 32: 590-607.

Van de Ven, A. H., \& Garud, R. 1989. A framework for understanding the emergence of new industries. In R. S. Rosenbloom \& R. Burgelman (Eds.), Research on technological innovation management and policy, vol. 4: 195-225. Greenwich, CT: JAI Press.

Van de Ven. A. H., \& Poole, M. S. 1995. Explaining development and change in organizations. Academy of Management Review, 20: 510-540.

Virany, B., Tushman, M. L., \& Romanelli, E. 1992. Executive succession and organization outcomes in turbulent environments: An organization learning approach. Organization Science, 3: 72-91.

Walsh, J. P. 1995. Managerial and organizational cognition: Notes from a trip down memory lane. Organization Science, 6: 280-321.

Yates, B. W. 1984. The decline and fall of the American automobile industry. New York: Empire Books.

Yin, R. 1984. Case study research: Design and methods. Beverly Hills, CA: Sage.

Zajac, E., \& Bazerman, M. 1991. Blind spots in industry and competitor analysis: Implications of interfirm (mis)perceptions for strategic decisions. Academy of Management Review, 16: 37-56.

Zammuto, R. F. 1988. Organizational adaptation: Some implications of organizational ecology for strategic choice. Journal of Management Studies, 25: 105-120.

Zander, U., \& Kogut, B. 1995. Knowledge and the speed of the transfer and imitation of organizational capabilities: An empirical test. Organization Science, 6: 76-92.

Zucker, L. G. 1983. Organizations as institutions. In S. B. Bacharach (Ed.), Research in the sociology of organizations, vol. 2: 1-47. Greenwich, CT: JAI Press.

Richard Pouder is an assistant professor of management at Clemson University. He received his $\mathrm{Ph}$.D. from the University of Connecticut. His research interests include strategic, institutional, and cognitive processes in areas such as innovation and downsizing.

Caron H. St. John is an associate professor of management at Clemson University. She received her Ph.D. from Georgia State University. Her research interests include industry dynamics, competitive processes, and their influence on technology and manufacturing strategies. 